\title{
Status and Actual Condition Analysis for Current Operational Cases of Care Farms in South Korea
}

\author{
Sun Jin Jeong ${ }^{1}$, Jan Hassink ${ }^{2}$, Gyung Mee Gim¹, Sin Ae Park ${ }^{3,4} *$, and Seon Ok Kim ${ }^{4}$ \\ ${ }^{1}$ Agricultural Research Division, National Institute of Horticultural and Herbal Science, Rural Development Administration, Jeonju 55365, \\ South Korea \\ ${ }^{2}$ Plant Sciences Group, Wageningen University and Research Centre, the Netherlands \\ ${ }^{3}$ Department of Environmental Health Science, Sanghuh College of Life Science, Konkuk University, Seoul 05029, South Korea \\ ${ }^{4}$ Horticultural Therapy, Graduate School of Agriculture and Animal Science, Konkuk University, Seoul 05029, South Korea
}

\begin{abstract}
The objective of this study was to investigate the current situations of farms in South Korea which provide care farming activities in order to develop and settle care farms. A questionnaire that includes 60 questions about resources, clients, management, background of establishment, budget, manpower, organization, etc. was developed by the researchers. The survey was conducted by email and phone interview in the period of July to August, 2016. Five farms were participated in this study. As the results, each farm had a different size of land, about 744 - 39,670 $\mathrm{m}^{2}$. The farms were classified by different types of farming activities such as cultivating horticultural crops or cultivating horticultural crops and raising animals. The background of farmers was health, special education, social welfare or professional farmer. The income sources were from care farming programs, educational program, and crop production. The participants in the care farm were children with or without disability, adolescents, adolescents with behavior problem, adults, adults with mental disability or developmental disability, mental illness, dementia, addict, etc. The major activities in care farms were plant cultivating, harvesting, garden maintenance, cooking by using harvest, crop processing, waling in the farm, caring for animals, dealing with farm work equipment, and farming activity with local residents, etc. The participation duration was $25 \%$ for one-day experience, less than two weeks in a week, and more than six months, respectively. To settle and develop care farming of South Korea, the concept, clients, operation, professional manpower, policy, support, etc. should be established.
\end{abstract}

Keywords: agro-healing, gardening, green care, social farming

\section{Introduction}

In current trends of Korean agriculture, interest has been shifting to agro-healing linking people's health and agricultural experience. As agro-healing has been expanding in the various forms of rural experience activities, interest and investment in agro-healing which pursues human health and healing along with income from farming, is increasing nowadays.

Agro-healing is defined as an industry and activities that promote the psychological, social, physical, and cognitive

This paper is supported by the Rural Development Administration's Agricultural Science and Technology Development Project (Project No: PJ01033301). Received: September 14, 2017, Revised: September 22, 2017, Accepted: September 25, 2017

*Comesponding author: sapark42@konkuk.ac.kr 
health of the people through agricultural and rural resources (plant, animal, rural environment, and rural culture) or related activities and output (Gim et al., 2013a). Agro-healing is to obtain effects of recovery and rehabilitation of a person with a mental or physical illness or disability, as well as those who are expected to return to school, such as school maladjusted students, inmates and drug addicts through participation of farming activities. This agro-healing can fall largely into three categories - a healing-centered type that has purpose of healing, an employment-oriented type that provides professional education and training to socially disadvantaged people, linking them to employment and labor markets, and an education-centered type that provides education to meet the educational needs of students (Di Iacovo and O'Connor, 2009; Haubenhofer et al., 2010). For this, various activities such as horticultural therapy, animal-assisted therapy, wild life therapy, ecological therapy, forest healing, etc. are carried out (Di Iacovo and O'Connor, 2009; Haubenhofer et al., 2010).

Agro-healing advanced countries in Europe such as the Netherlands, Belgium, France, Italy, Germany, the United Kingdom and Slovenia have developed different concepts of agro-healing, objectives and policy support depending on the socio-economic situation and social demand of each country and through the agro-healing, they provide new forms of treatment resources for the socially underprivileged and the community, contributing the income of farm household (Dessein and Bettina, 2010; Di lacovo and O'Connor, 2009; Hine et al., 2008). In the Netherlands, welfare and agriculture-related national institutions provide policy and financial support for agro-healing, and the state support center has developed a quality system for care farms and conducted quality control that covers care farm owner, care farm associations and related government ministries. In addition, the care farm, which has been approved in connection with the National Health Insurance, is recognized as officially healthy organization and is promoted through long-term linkage with health insurance (Hassink and van Dijk, 2006). In Belgium, the policy support for agro-healing is being centered on the Department of Agriculture and Fisheries, and the Flemish Support Center for Green Care, a private institution-based support center was established to invigorate agro-healing activities and has taken a role of providing information, consulting and connecting services between care farms and clients, etc. (O'Connor et al., 2010).

In South Korea, with promotion of the 6th industrialization plan of the government, multi-functional elements of farming in addition to the production function of agriculture has been on spotlight and there is an increasing interest in the healing function of agriculture and rural areas beyond rural tourism and rural experience. However, domestic agrohealing is at a very early stage, and the concept of agro-healing, subject, national policy and support measures are also under discussion. In some municipalities, an agro-healing instructor course has been adopted to introduce the concepts and roles of argo healing. In fact, individual farmers employ the healing-related qualification holders to operate the agro-healing program on their own.

Therefore, this study was carried out to grasp the status and actual condition of domestic farm households who provide similar activities with agro-healing to establish and develop domestic agro-healing.

\section{Study Methodology}

\section{Research method}

In order to investigate the current state of domestic care farms, a total of 19 sites known as care farms in Korea were selected through internet search and recommendation of experts. Five of them hoped to participate in this study. Among the care farms linked to the education farms conducted by the Rural Development Administration, the selected are those farm households whose main purpose and income sources of the experience programs are healing, and which targeted those who need helps such as disabled people, problem youth, dementia patients, unemployed people and homeless 
people.

For this survey, five questionnaires were developed by experts in the related fields. The questionnaire consisted of 60 questions - overview of care farm (1 question), resources (4 items), subjects (3 items), general status (5 items), establishment background (1 question), finance (8 questions), manpower (6 questions), activities (18 questions), subject management (6 questions) and organization ( 8 questions). The survey consisted of email and telephone interviews. The study period lasted for about one month from July to August 2016.

\section{Data analysis}

Data obtained from a total of five farms participated in this survey was analyzed statistically by means of Microsoft Excel to calculate average value and percentage (Office 2007, Microsoft Corp., Redmonf, WA).

\section{Results and discussion}

\section{Scale of care farms and major resources by type}

Agro-healing can be divided into various forms depending on the programs, participants, and circumstances, which are provided with the two objectives of agricultural production and healing (Hine et al., 2008; Sempik et al., 2010). In terms of agriculture, various levels of agricultural activities (growing crops, horticulture, livestock farming, farm machinery, forest management, etc.) are provided and healing aspects include health care, social rehabilitation and education activities (Gim et al., 2013b).

The sizes of the five care farms (A, B, C, D, and E) investigated in this study vary, ranging from about $744 \mathrm{~m}^{2}$ to about $40,470 \mathrm{~m}^{2}$. The farm types were divided into horticultural cultivation type ( 3 sites) and mixed type ( 2 sites) that combines horticulture with animal mixed type. It is a plant-centered farm mainly for crops and horticulture. As a kind of livestock mixed type, there are very few kinds of livestock such as chickens and rabbits. Therefore, the proportion of livestock is very low compared to European care farms. Farm A is $1,776 \mathrm{~m}^{2}$ in size and was mainly used for activities such as cultivation of horticultural crops (herbs, leafy vegetables, fruit trees, cotton, flowers) and production of processed products using harvest. Farm B is $4,300 \mathrm{~m}^{2}$, mainly working on growing horticultural crops (fleshy plants, leafy vegetables, herbs, etc.), craftsman work and animal husbandry (chickens). Farm C is $40,470 \mathrm{~m}^{2}$, mainly farming horticultural crops (herbs, fruits and vegetables). Farm D is $744 \mathrm{~m}^{2}$ in size, mainly for the cultivation of horticultural crops (herbs, flowers, leafy vegetables) and livestock (chickens, rabbits). The scale of farm $\mathrm{E}$ is $3,100 \mathrm{~m}^{2}$, and it is a farmhouse

Table 1. Main resource and size of care farm in South Korea.

\begin{tabular}{|c|c|c|c|c|}
\hline Farm & Size of farm & Main activity & Resources & Facility \\
\hline A & $1,776 \mathrm{~m}^{2}$ & Horticulture & Horticulture: herbs, leafy vegetables, fruit vegetables, cotton, flowers, etc. & Greenhouse \\
\hline B & $4,300 \mathrm{~m}^{2}$ & $\begin{array}{l}\text { Horticulture } \\
\text { and animal }\end{array}$ & $\begin{array}{l}\text { Horticulture: Japanese apricot, plums, herbs, succulents } \\
\text { Crops: corn, lettuce, watermelon, oriental melon, cucumber, radish, cabbage } \\
\text { Livestock: chicken (egg) }\end{array}$ & $\begin{array}{l}\text { Indoor } \\
\text { activity room }\end{array}$ \\
\hline $\mathrm{C}$ & $40,470 \mathrm{~m}^{2}$ & Horticulture & Horticulture: herbs, cherry tomatoes & - \\
\hline $\mathrm{D}$ & $744 \mathrm{~m}^{2}$ & $\begin{array}{l}\text { Horticulture } \\
\text { and animal }\end{array}$ & $\begin{array}{l}\text { Horticulture: herbs, flowers, garden vegetables } \\
\text { Livestock: Chicken, Rabbit }\end{array}$ & $\begin{array}{l}\text { Outdoor } \\
\text { activity place }\end{array}$ \\
\hline $\mathrm{E}$ & $3,100 \mathrm{~m}^{2}$ & Horticulture & $\begin{array}{l}\text { Gardening: foliage plants, succulents, flowers (roses, mandrill, pansy, } \\
\text { a marvel-of-Peru, magnolia) }\end{array}$ & - \\
\hline
\end{tabular}


focused on horticultural cultivation (succulent plants, foliage plants, flowers). Three of the five facilities are equipped with educational experience facilities where facilities for planting and experiencing are available. In the case of the Dutch care farm, there are restaurants, tea rooms, shops, room of dedicated programs for elderly people with dementia, indoor and outdoor rest areas, kitchens, toilets, garbage disposal space, administrative office, wooden workroom, warehouse, parking lot, vehicles for customer transportation (Jeong et al., 2016a). However, there are very few types of facilities that support agro-healing service activities.

Agriculture-related resources are classified into main crops according to farming type, but in reality, a complex composition is needed to allow participants to experience various resources from their points of view. Even when weather conditions are not good, indoor and outdoor experience and resting space where participants can perform various agricultural activities are needed, and the scale of farms will not be a limiting factor. The diversity of the farm should be respected rather than the limitation of participation size through related laws, etc.

\section{Background of care farmers and motivation}

As the result of examining the background of the farm owners who established the care farm, most of them have experiences of health care, special education and social welfare among five farms which showed that there are many farm owners who have experience in healing service (Table 2). The motivation for starting a care farm includes that they have family members who need help from families or surrounding people so they want to heal them (Table 2). Or they want to realize public value through agriculture, confirm the social functions of agriculture, to expand added value, or to present a new model of vocational rehabilitation for the disabled.

In the Dutch care farm, the owner wanted to do something meaningful in life, such as providing a place to work for those in need, and wanted to offer a more valuable alternative than the existing agriculture (Jeong et al., 2017). Owners started with similar motivation and they are qualified with licenses such as social service worker, Korean welfare gardeners, and psychiatrists to provide agro-healing services to those who need help. In many cases, care farm owners often started the farms as a background for healing services. Even though experts such as medical, welfare, and education are involved, it is considered important to start from the agricultural activities and rural resources as the basis of

Table 2. Background of care farmers and motivation to start care farms.

\begin{tabular}{|c|c|c|c|}
\hline Farm & Background & Qualifications of the instructor & Motivation to start care farms \\
\hline A & Health care & $\begin{array}{l}\text { Social welfare worker, } \\
\text { Korean horticultural therapist }\end{array}$ & $\begin{array}{l}\text { To realize public value through the healthy life of me and my family and } \\
\text { neighbors }\end{array}$ \\
\hline B & Farmer & $\begin{array}{l}\text { Social welfare worker, } \\
\text { Korean horticultural therapist, } \\
\text { Engineer floral design }\end{array}$ & For family healing \\
\hline $\mathrm{C}$ & $\begin{array}{l}\text { Farmer, } \\
\text { Health care }\end{array}$ & $\begin{array}{l}\text { Psychiatrist, } \\
\text { Korean horticultural therapist }\end{array}$ & $\begin{array}{l}\text { To identify the social function of agriculture and to expand added value } \\
\text { through it } \\
\text { An agricultural approach to the healing and social return of chronic mental } \\
\text { illnesses }\end{array}$ \\
\hline $\mathrm{D}$ & Special teacher & $\begin{array}{l}\text { Special education, } \\
\text { Korean cuisine }\end{array}$ & $\begin{array}{l}\text { For beginning of agriculture and vocational education course for special } \\
\text { education students }\end{array}$ \\
\hline E & Social welfare & Social welfare worker & $\begin{array}{l}\text { A new model of vocational rehabilitation for the disabled by expanding } \\
\text { the scope of vocational rehabilitation and increasing the income for the } \\
\text { severely disabled }\end{array}$ \\
\hline
\end{tabular}


participation. Therefore, it is necessary to have an understanding and sufficient experience of agricultural infrastructure expertise centering on daily life or yearly life of agriculture, and rural area.

\section{Types and characteristics of participants}

As the result of examining the types of participants in the care farm program, it was found that children with or without disability (13\%), middle and high school students and adults (10\%), adolescents with behavioral problems (13\%), adults with intellectual disability (10\%) or developmental disability (13\%), mental patients (10\%), dementia patients (7\%) and addicted patients (7\%), etc. Adults with developmental disabilities, adolescents with behavioral problems, children with special needs are in four out of five farms, accounting for large portion and 2 out of 5 farms include addiction, dementia patients, and general kindergarten children (Fig. 1). Four out of five places require participants to have conditions such as disability grades, chronic illnesses, and special school students. Similarly, Dutch care farms have priority in terms of participation - in the order of intellectual disability, mental illness, adolescent with behavioral problems, and demented elderly. Recently, there has been a significant increase of customers such as young people with special education and those with acquired brain disease. Among the unlisted types of domestic care farms were those with burnout syndrome, long-term unemployment, (former) inmates, and those with acquired brain disease (Jeong et al., 2016b).

\section{Participating activities and operation types in care farms}

The activities provided by European care farms vary according to the type of agriculture resources, the characteristics of the participants, the environment, and depending on the farms or institutions providing the agro-healing, animalassisted care, crop production and horticultural treatment can be provided. According to the agro-healing program, there may be agro-healing which focuses on agricultural production, and on the contrary there may be agro-healing which focuses on healing (Gim et al., 2013a). As the result of investigating the activities carried out in five care farms in Korea, the most frequent activities were planting and harvesting, managing gardening fields, and making food using harvested products ( 4 places), then processing the harvest, hiking in farms (3 sites) cleaning, handling animals, handling agricultural equipment, and agricultural activities with local residents ( 2 places $)$ were second most frequent. The percentage of

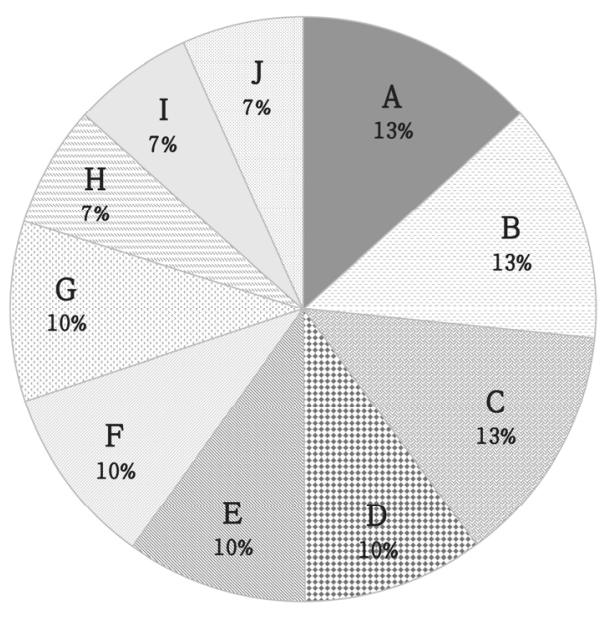

Figure 1. Kinds of participants in care farming.

$A=$ Children with special needs; $B=$ Adolescents with behavior problems; $C=$ Adults with developmental disabilities; $D=A d u l t s$ with intellectual disabilities; E=People with mental illness; F=Adolescents; $\mathrm{G}=$ Adults; H=Kindergartener; I=Addicted patients; $\mathrm{J}=$ Dementia inpatient. 
different activities taking place in farms is shown in Fig. 2. Activities in the Dutch care farm do not include product sales, restaurant serving, beekeeping, forest conservation and woodworking (Jeong et al., 2016a).

Duration of participants in the agro-healing program vary, ranging from one day to less than one or two weeks to more than 6 months, which account for $25 \%$ respectively. More than 1 day to less than 1 week, more than 2 weeks to less than 4 weeks and more than one month to less than six month account for $8.3 \%$ respectively (Fig. 3). The farms A and E operated five times a week for an average of 9 hours per day, with an average of 300 to 500 participants per week. As for farm B, C, and D, 25 to 50 people per week were participating in the program.

\section{Income sources and support system of care farm}

The main income sources for the care farm was healing programs, education programs, and crop production (Fig. 4). In the case of farms $\mathrm{A}$ and $\mathrm{C}$, the main source of revenue was the healing program using agriculture, while Farm $\mathrm{D}$ was the education program. Most of the main income of Farm B was crop production according to the survey. Each farm applied for national support projects (Ministry of Culture, Sports and Tourism, Ministry of Education, Community Chest of Korea, Rural Development Administration, Employment Promotion Agency for the Disabled, etc.) to receive support such as operating expenses and labor cost. In the case of Farm C, the agro-healing program for chronically mentally ill patients was conducted three times a week through the support of the Community Chest of Korea, and the agro-healing clinical practice course was run with the support project of the Employment Promotion Agency for the Disabled. In

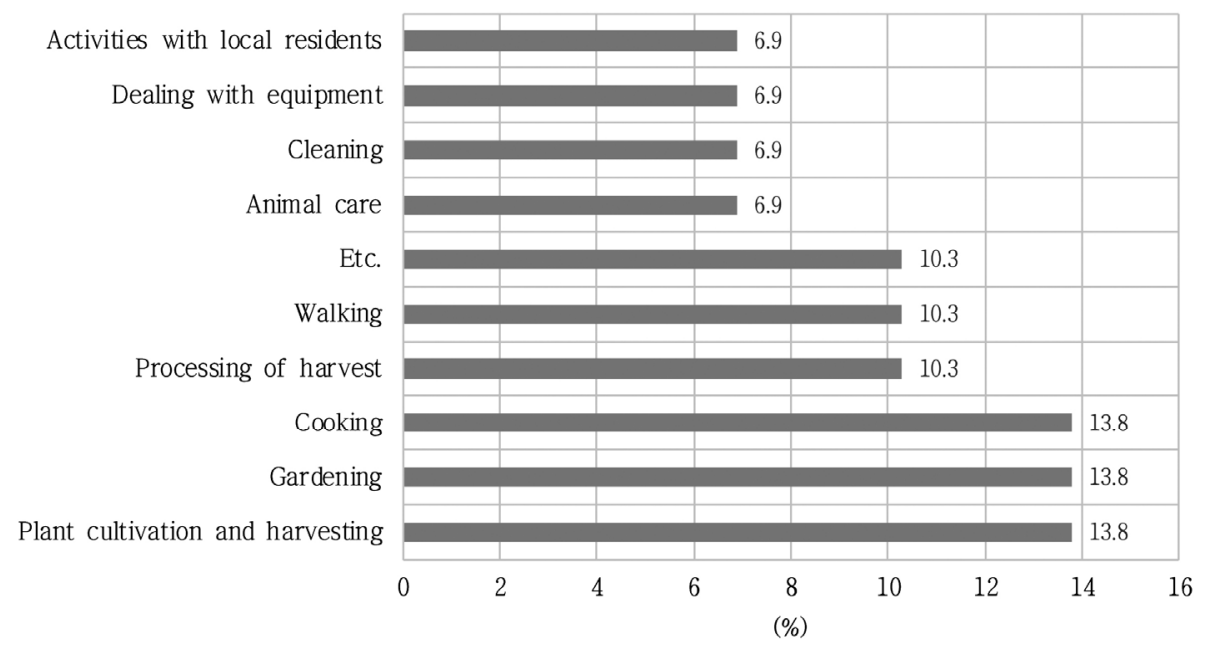

Figure 2. Kinds of care farming activities.

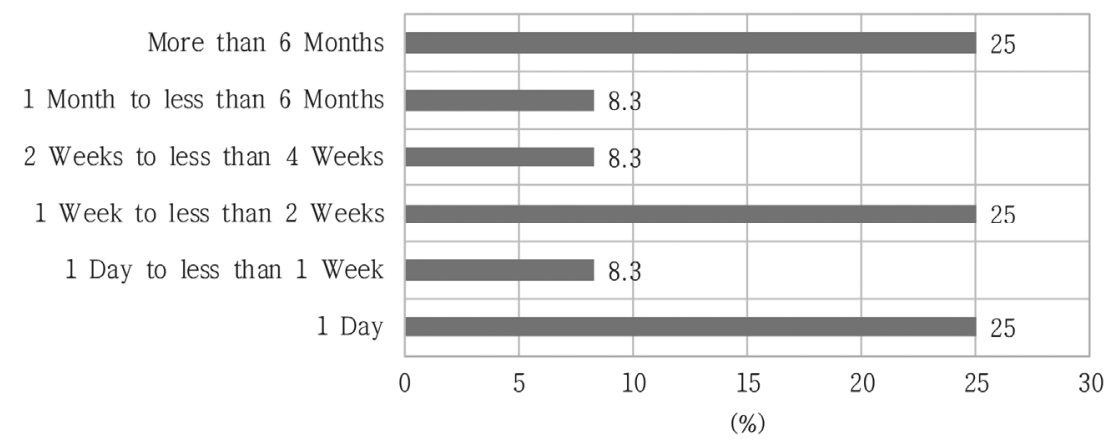

Figure 3. Duration of participation in care farm. 


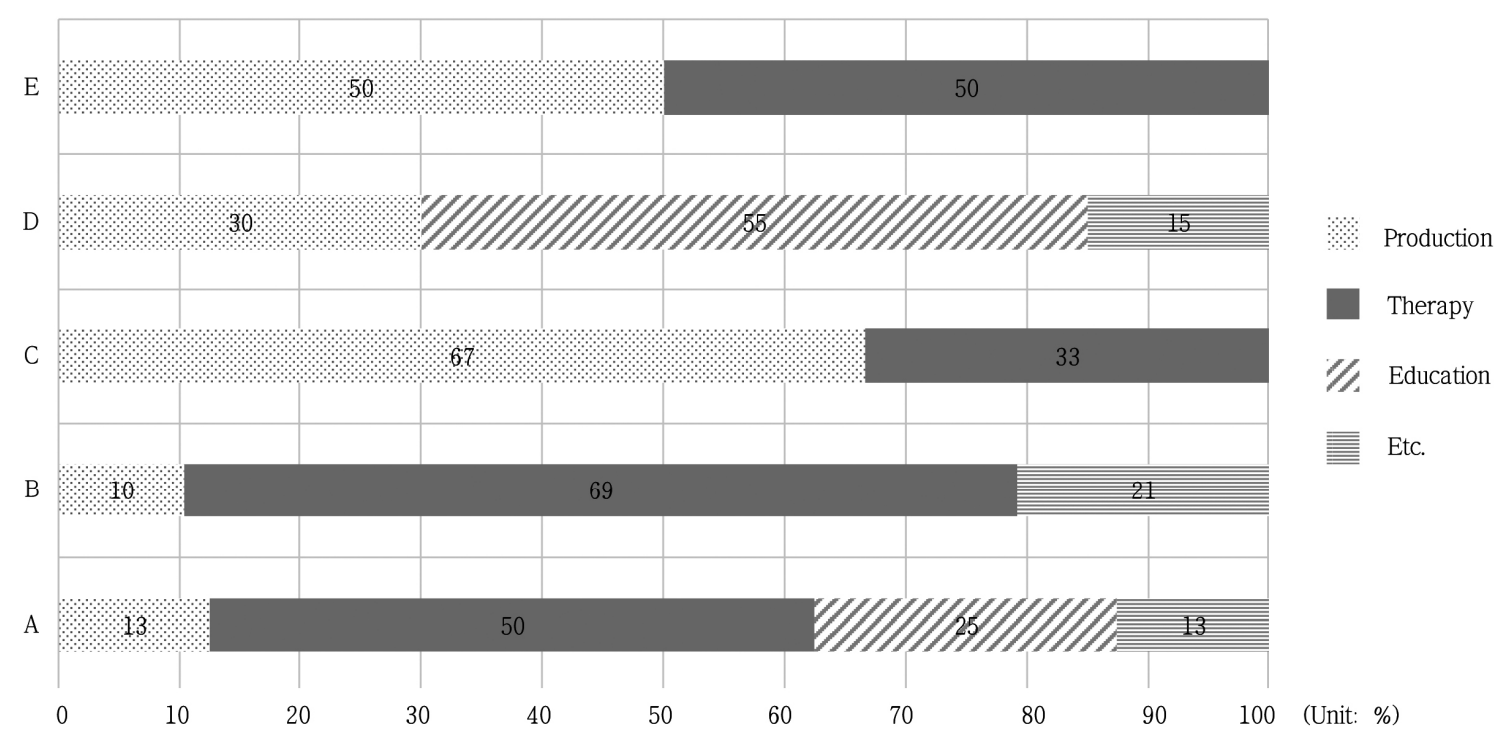

Figure 4. Income sources of the farms.

addition, the agro-healing program through the agro-healing pilot project was run from the support of Rural Development Administration. The main income source of Farm E was healing and crop production. From the perspective that the main income source of the farm should be the production and sale of agricultural products, and the provision of healing services through programs, it is found out that improvement of the healing service using agriculture is necessary in the future. Comprehensive support will be needed for diversity of programs, customized services considering the characteristics of participants, and improvement of facilities. This part should be accompanied by studies related to the support of policy departments such as agriculture, health and social welfare.

Although farmers' interest in agro-healing is increasing, domestic agro-healing is currently in its early stages, seeking the concept of agro-healing, national policies and support measures for domestic situation. As the result, the number of farms providing the agro-healing services was insufficient so that it was impossible to grasp the overall situation. In order to establish and activate domestic agro-healing, it is urgent to establish agro-healing concept, object, mode of operation, cultivation of professional manpower, national policy and support plan for domestic situation. As a result of investigating the necessary parts to start and maintain the agro-healing in the farmhouse, it was necessary to support the land, facilities and initial capital that can help provide the care farm service along with support for deregulation in facility installation and convenient facilities. In addition, medical insurance should be applied to agro-healing, so that not only disabled persons and patients but also ordinary people who need healing can participate in the agro-healing service, and it is necessary to build the agro-healing program manual and strengthen the capacity of the practitioners (Gim et al., 2013a).

In the Netherlands, which is an advanced country of agro-healing, the Ministry of Health, Welfare and Sport is responsible for legislation and policy making including social assistance law (WMO) related to agro-healing, health insurance law, health benefits, medical care for the elderly, retirement recuperation, elderly recuperation, mental health, child abuse and adolescent law, providing administrative and financial support for agro-healing. The Ministry of Agriculture, Nature, and Food Quality develops agro-healing related policies (Jeong et al., 2016c). In addition, the National Support Center, a not-for-profit organization was established to operate the Association of Green Care Farmers and Regional Groups to protect the rights of care farmers (O'Connor et al., 2010). The National Support Center develops a quality system for care farms and carries out quality control, including care farms, care farm associations, and 
government departments. Farmers who meet the qualification criteria of the care farm are granted a quality mark and are recognized as official health institutions for the care farms approved in connection with the National Health Insurance. For longer term, they are promoted by being connected to health insurance (Hassink and van Dijk, 2006). In Belgium, the Department of Agriculture and Fisheries plays a central role in providing diverse policy supports for the activation of the agro-healing. As a private organization, the Flemish Support Center for Green Care promotes agro-healing by connecting farmers and participants (O'Connor et al., 2010).

In the meantime, people have very low awareness and experience of agro-healing, but they are reported to have a high interest and intention in agro-healing (Park et al., 2017). In addition, activities similar to agro-healing have been used for experiential, leisure, and educational purposes, but the public has a strong desire to use agriculture for recreation and healing (Park et al., 2017).

In recent years, farmers and the public are increasingly interested in agro-healing and their willingness to participate is growing as well. However, since there is no foundation for such policies and systems, it is urgent to define and establish many things including the concepts, objects, operation type, human resource cultivation, national policies, and support measures. In future research, it will be necessary to investigate the awareness and interest of agro-healing by expanding the farmers who run the education and experience agricultural program in addition to the farmers who operate agro-healing.

\section{Summary}

This study was conducted to find out the status and actual conditions of domestic farmers who provide similar activities to agro-healing with a view to establish and develop domestic agro-healing in Korea. The survey was carried out through email and telephone interviews for one month from July to August 2016. A total of five farmers participated in this study. Currently the number of farms providing the agro-healing service is insufficient so that it is not possible to grasp the overall situation. So far farmers and the public have been increasingly interested in and participating in agro-healing. However, since there is no foundation for such policies and systems, it is urgent to define and establish many things including the concepts, objects, operation mode, human resource cultivation, national policies, and support measures. In future research, it will be necessary to investigate the awareness and interest of agro-healing by expanding the farmers who run the education and experience agricultural program in addition to the farmers who operate care farming.

\section{References}

Dessein, J. and B. Bettina. 2010. The economics of green care in agriculture. Loughborough, UK: Loughborough University.

Di Iacovo, F. and D. O'Connor. 2009. Supporting policies for social farming in europe. Progressing Multifunctionality in Responsive Rural Areas.

Gim, G.M., J.H. Moon, S.J. Jeong, and S.M. Lee. 2013a. Analysis on the present status and characteristics of agro-healing in Korea. J. Agric. Ext. Community Dev. 20(4):909-936. DOI: 10.12653/jecd.2013.20.4.0909

Gim, G.M., J.H. Moon, S.J. Jeong, S.M. Lee, K.Y. Kim, and D.H. Kil. 2013b. A strategic study on definition and classification of the agro-healing in Korea. J. Korean Soc. People Plants Environ. 2013(2):45-47. (Abstr.)

Hassink, J. and M. van Dijk. (Eds.) 2006. Farming for health: green-care farming across europe and the united states of america. vol. 13. Springer Science \& Business Media.

Haubenhofer, D. K., M. Elings, J. Hassink, and R. E. Hine. 2010. The development of green care in western european countries. EXPLORE: J. Sci. Heal. 6(2):106-111. DOI: 10.1016/j.explore.2009.12.002 
Hine, R., J. Peacock, and J. N. Pretty. 2008. Care farming in the UK: evidence and opportunities. Report for the National Care Farmin Initiative (UK): University of Essex. Retrieved from https://www.slideshare.net/ElisaMendelsohn/carefarming-in-the-uk-evidence-and-opportunities?qid=05da74e3-88e1-4ffb-af9f-ccd6d3b73197\&v=\&b=\&from_search=1

Jeong, S.J., J. Hassink, G.M. Gim, E.H. Yoo, Y.A. Jang, S.M. Lee, and D.K. Park. 2016a. Program planning and operation of agro-healing, korea-netherlands care farming series VI, Jeonju, Korea: Rural Development Administration.

Jeong, S.J., J. Hassink, G.M. Gim, E.H Yoo, Y.A. Jang, S.M. Lee, and D.K. Park. 2016b. Business status and operating systems of agro-healing, korea-netherlands care farming series V. Jeonju, Korea: Rural Development Administration.

Jeong, S.J., J. Hassink, G.M. Gim, E.H Yoo, Y.A. Jang, S.M. Lee, and D.K. Park. 2016c. Support systems of agro-healing, korea-netherlands care farming series II. Jeonju, Korea: Rural Development Administration.

Jeong, S.J., K.S. Han, Y.A. Jang, G.M. Gim, and S.M. Lee. 2017. Study on methodology and evaluation system of care farm ing(Rural Development Administration Research Report. PJ010333). Retrieved from http://www.ndsl.kr/ndsl/commons /util/ndslOriginalView.do?cn=TRKO201700006439\&dbt=TRKO

O'Connor D., M. Lai., and S. Watson. 2010. Overview of social farming and rural development policy in selected EU member states, NRN Joint Thematic Initiative on Social Farming. Brussel, Belgium: Europena Network for Rural Development.

Park, S.A., A.Y. Lee, G.J. Lee, W.L. Lee, S.J. Bae, B.J. Park, and D.S. Kim. 2017. A study of awareness and needs for care farming in South Korea. J. Korean Soc. People Plants Environ. 20(1):19-24. DOI: /10.11628/ksppe.2017.20.1.019

Sempik, J., R. Hine, and D. Wilcox. 2010. Green care: a conceptual framework. A report of the working group on the health benefits of green care. COST. Retrieved from https://www.slideshare.net/ElisaMendelsohn/green-care-a-conceptual-fra mework 